\title{
Plasmolysis and Vital Staining Reveal Viable Oospores of Peronospora effusa in Spinach Seed Lots
}

Sridhara G. Kunjeti, Department of Plant Pathology, University of California-Davis, Salinas 93905; Amy Anchieta, United States Department of Agriculture-Agricultural Research Service (USDA-ARS), Salinas, CA 93905; Krishna V. Subbarao, Department of Plant Pathology, University of California-Davis, Salinas; Steven T. Koike, University of California Cooperative Extension, Salinas; and Steven J. Klosterman, USDA-ARS, Salinas

\begin{abstract}
Kunjeti, S. G., Anchieta, A., Subbarao, K. V., Koike, S. T., and Klosterman, S. J. 2016. Plasmolysis and vital staining reveal viable oospores of Peronospora effusa in spinach seed lots. Plant Dis. 100:59-65.

Production of oospores by Peronospora effusa, the causal agent of downy mildew on spinach (Spinacia oleracea), was reported on spinach seed over three decades ago. In view of the rapid proliferation of new races of $P$. effusa worldwide, seedborne transmission of this pathogen has been suspected but methods to test the viability of seedborne oospores have not been available. Eighty-two seed lots of contemporary spinach cultivars were evaluated for the presence of $P$. effus $a$ using a seed-wash method and the sediment was examined by microscopy. Of the analyzed seed lots, $16 \%$ were positive for oospores and an additional $6 \%$ for sporangiophores characteristic of $P$. effusa. Application of a $P$. effusa-specific quantitative polymerase chain reaction assay showed that $95 \%$ of the 59 tested seed lots were positive for $P$. effusa. The viability of oospores from five seed lots that

were proven to carry the pathogen from the above tests was tested using two independent methods, one involving plasmolysis and the other trypan blue staining. The oospores plasmolyzed in $4 \mathrm{M}$ sodium chloride and were deplasmolyzed in water, demonstrating an active and viable cell membrane. Similarly, viable oospores failed to take up the trypan blue stain. Overall, 59\% of the oospores were viable in the plasmolysis test and $45 \%$ with the trypan blue test. These results indicate the presence of $P$. effus $a$ oospores in contemporary spinach seed lots, and suggest that the transmission of viable oospores of $P$. effus $a$ in spinach seed does occur. Elimination of the pathogen on seed, in addition to other management approaches, will be useful in reducing the extent and severity of downy mildew on spinach crops and diminishing pathogen spread through seed.
\end{abstract}

Downy mildew of spinach (Spinacia oleracea) is caused by the obligate biotrophic oomycete Peronospora effusa (Choi et al. 2007, 2015). Spinach downy mildew was first reported in 1824 and 1890 in England and the United States, respectively (Richards 1939; Sherf and MacNab 1986). Currently, downy mildew is recognized as the most widespread and destructive disease of spinach (Correll et al. 2011; Koike et al. 2011), causing extensive losses under favorable conditions (LeStrange and Koike 2012). Like many downy mildew pathogens, $P$. effusa requires cool, wet conditions with a temperature optimum between 15 to $21^{\circ} \mathrm{C}$ for disease development (Richards 1939).

Closely related downy mildew pathogens such as $P$. schachtii and $P$. effusa are host specific, causing symptoms only on beet and spinach, respectively (Byford 1967; Klosterman et al. 2014). The symptoms associated with spinach downy mildew are especially problematic for fresh-market production. Typically, the first symptoms are chlorotic spots on the upper leaf surface, which render spinach leaves unmarketable for fresh market. Pale yellow spots with gray to purple downy growth on primarily the abaxial side of

Corresponding author: S. J. Klosterman;

E-mail: Steve.Klosterman@ars.usda.gov.

Mention of trade names or commercial products in this publication is solely for the purpose of providing specific information and does not imply recommendation or endorsement by the United States Department of Agriculture (USDA). USDA is an equal opportunity provider and employer.

*The $\boldsymbol{e}$-Xtra logo stands for "electronic extra" and indicates that one supplementary figure, two supplementary tables, and three supplementary videos are published online.

Accepted for publication 16 July 2015.

http://dx.doi.org/10.1094/PDIS-06-15-0672-RE

This article is in the public domain and not copyrightable. It may be freely reprinted with customary crediting of the source. The American Phytopathological Society, 2016. the leaf are typical under optimal weather conditions (Koike et al. 2011).

Spinach is sold as fresh-market clipped (baby and teenage) or bunched products, in addition to canned and frozen commodities (Koike et al. 2011). California is the leading U.S. producer of fresh-market spinach, with $66 \%$ of the area planted and $59 \%$ of the production value, followed by Arizona with $23 \%$ of the area planted and $30 \%$ of the production value (USDA 2014). For baby leaf spinach, seeding rates are typically in the range of 8.5 to 10.0 million seeds/ha but are slightly lower for teenage spinach (Koike et al. 2011); these crops can be harvested as early as 21 days after planting (Feng et al. 2014). These high planting densities coupled with overhead irrigation provide conducive conditions for downy mildew development. Spinach seed for this crop production originate mainly from the Pacific Northwest of the United States and in Northern Europe because of the long day length requirement for seed production (Navazio and Colley 2007).

Spinach downy mildew can be effectively managed by applying fungicides in conventional production (LeStrange and Koike 2012); however, no effective fungicides are available for organic spinach production. Continued development and maintenance of plant resistance, particularly for the organic sector, is complicated by the rapid appearance of new pathogen races (Correll et al. 2011). Though the disease was first identified in the 1800 , only three races of $P$. effusa were identified prior to 1990 (Morelock 1999; Smith 1950; Smith et al. 1961, 1962). Remarkably, since 1990, 12 new races of $P$. effusa have emerged (Correll et al. 2011; Feng et al. 2014; Koike and Correll 2014), and some of these newer races have overcome all known genetic resistance (Irish et al. 2003, 2007). Based on the response of the differential cultivars, six downy mildew resistance loci (RPF1 to RPF6) have been identified (Feng et al. 2014). Each of these genes has shown resistance to one or more races of $P$. effusa. Development of cultivars containing combinations of the six genes will be invaluable for downy mildew management in both conventional and organic production systems. Use of resistant cultivars and pathogen-free seed are important for increasing the productivity of organic spinach (Abawi et al. 2014; Navazio and Colley 2007). 
Detection and elimination of the primary inoculum is an important step in curtailing the spread of spinach downy mildew. A quantitative polymerase chain reaction (qPCR) method was developed for detecting DNA of $P$. effusa in leaves and from sporangia collected in spore trap samples (Klosterman et al. 2014) but this detection assay does not determine pathogen viability. Because oospores are the longterm survival structures for oomycetes, it is important to determine their viability (Etxeberria et al. 2011). The precise duration of survival is not known for $P$. effusa oospores but oospores of $P$. viciae and $P$. destructor remain viable in soil for 15 months to 25 years, respectively (MacKay 1957; Van Der Gaag and Frinking 1997). The oospores of $P$. effusa, $P$. manshurica, and $P$. arborescens overwinter in soybean, spinach, and opium poppy debris, respectively (Lai et al. 2004; Montes-Borrego et al. 2009; Navazio and Colley 2007). Various stains such as tetrazolium chloride (TTC), nitroblue tetrazolium chloride (NBT), Phloxine B, trypan blue, and tetrazolium bromide (MTT) have been used to assess the viability of oospores (Etxeberria et al. 2011; Kjøller and Rosendahl 1998; Roongruangsree et al. 1988; Sutherland and Cohen 1983; Van Der Gaag and Frinking 1997). The majority of these stains yielded nonspecific reactions and, therefore, are unreliable to assess oospore viability (Etxeberria et al. 2011). In addition to staining techniques, plasmolysis methods have also been used to test the viability of Pythium and Phytophthora spp. (Etxeberria et al. 2011; Groves and Ristaino 2000; Lumsden 1980; McCarren et al. 2009).

The extent of $P$. effusa infestations in modern seed lots is not known, although it is clear that $P$. effusa can be seedborne (Inaba et al. 1983; Navazio and Colley 2007). Oospores of $P$. effusa were detected in 6 of 11 spinach seed lots in a study conducted over three decades ago (Inaba et al. 1983). With the rapid appearance of new races of the spinach downy mildew pathogen (Feng et al. 2014) and the lack of control measures for an expanding organic spinach market, knowledge of current seed infestation levels is important for achieving a greater understanding of the disease epidemiology and for limiting the spread of downy mildew in the field.

The objectives of this study were to assess commercial spinach seed lots for the presence of seedborne $P$. effusa inoculum and in seed lots that were positive for oospores, to determine the viability of oospores.

\section{Materials and Methods}

Processing seed lots for detection of $\boldsymbol{P}$. effusa. Eighty-two seed lots were obtained from U.S. commercial spinach seed producers (Supplementary Table S1). Seed from each lot were evaluated for the presence of oospores using a seed-wash method. Depending on the numbers of available seed of each lot, 500 or 1,000 seeds from each lot were placed in $20 \mathrm{ml}$ of deionized water in a 50-ml Falcon tube (Fisherbrand) and vortexed (Vortex Genie2; Scientific Industries) for $5 \mathrm{~min}$ at high speed (speed control switch to position 10). The suspension was then placed on a rocker platform (Rocker II; Boekel Scientific) and agitated for $5 \mathrm{~min}$. The liquid was decanted into a 50-ml Falcon tube and centrifuged (Sorvall RC-5B; DuPont Instruments) at 4,000 $\times g$ for $10 \mathrm{~min}$. The supernatant was decanted and the pellet was resuspended in $500 \mu \mathrm{l}$ of the deionized water. A $25-\mu \mathrm{l}$ volume of the suspended pellet was placed on each of the three precleaned glass microscope slides, covered with a coverslip (22 by $22 \mathrm{~mm}$ ), and examined for the presence of $P$. effusa using a compound microscope (Olympus model BX60F; Olympus Optical Co. Ltd.) by adjusting the field of view to systematically cover the entire area of the coverslip. Images were captured using the Olympus DP70 camera attached to the microscope, and DP Controller software (version 1.2.1.108; Olympus Optical Co. Ltd.). The diameters of the oospores were measured using micrometer divisions of a hemacytometer as a reference.

For the oospore-positive seed lots, separate experiments to determine the numbers of oospores were repeated three times (for lots $22,24,25,29,30,36,37,49,56,57$, and 60) with less seed and a smaller volume of liquid than the experiment described above. Each replicate consisted of 100 seeds per seed lot, and $3 \mathrm{ml}$ of water was used to wash off the oospores in a 15-ml Falcon tube. After vortexing and rocking steps as described above, the supernatant was decanted into a 2-ml microcentrifuge tube and then centrifuged on a tabletop centrifuge (Eppendorf) at 5,000 $\times g$ for $10 \mathrm{~min}$. The pellet was resuspended in $100 \mu \mathrm{l}$ of deionized water, and two aliquots of $25 \mu \mathrm{l}$ from each tube (containing 100 seeds) were analyzed by microscopy using the procedure described above. The reported data are the average of three replicates with the corresponding standard errors of the mean.

Viability tests by the plasmolysis method. Plasmolysis testing was conducted using seed from five seed lots, where $>60$ oospores were detected (Table 1) using the method described by Etxeberria et al. (2011). The oospore suspension $(25 \mu l)$ was centrifuged (Eppendorf) for $5 \mathrm{~s}$ at $5,000 \times g$. The supernatant was removed and an equal volume $(25 \mu \mathrm{l})$ of hypertonic solution $(4 \mathrm{M} \mathrm{NaCl}$; Fisher Scientific) was used to resuspend the pellet, and observations were taken at 15-min, 30-min, 45-min, 18-h, and 24-h intervals. This experiment included three replicates and was repeated once. Oospores were classified as viable (plasmolyzed) or nonviable (nonplasmolyzed). For the reverse test (deplasmolysis), $10 \mu \mathrm{l}$ of the plasmolyzed oospore suspension was mounted on a microscope slide with a coverslip ( 22 by $22 \mathrm{~mm}$ ). While focusing the field on a plasmolyzed oospore, $15 \mu$ l of hypotonic solution (deionized water) was slowly added to the mount from the edge of the coverslip. The reverse process of deplasmolysis was nearly instantaneous following the addition of deionized water. Fifteen images per minute were taken in succession for time lapse evaluation. The iMovie (Apple) software was used to string the captured images together to make a video showing deplasmolysis of the contracting membrane. Viable (plasmolyzed) and nonviable (nonplasmolyzed) oospores were expressed as a percentage of the total oospores examined, and the reported numbers are the average of three replications with their corresponding standard errors of the mean. The data shown from this experiment were taken at $45 \mathrm{~min}$ and repeated twice for a total of three replicates.

Trypan blue staining. The same subset of oospore suspensions that was used for plasmolysis was also used to test oospore viability using trypan blue staining. The spore suspension $(25 \mu \mathrm{l})$ was centrifuged at $5,000 \times g$ for $5 \mathrm{~s}$ and the supernatant removed, to which an equal amount $(25 \mu \mathrm{l})$ of $0.4 \%$ trypan blue stain (Gibco by Life Technologies) was added. This was incubated for $1 \mathrm{~min}$ at room temperature, mounted on a glass slide, and examined under a compound microscope at $\times 40$. Viable oospores remained unstained but, in nonviable oospores, the trypan blue stain entered the central cavity of the spore. Images were captured as described above and repeated twice for a total of three replicates. The time lapse images were captured upon addition of trypan blue stain to microscope slides containing plasmolyzed and nonplasmolysed oospores and assembled with the iMovie (Apple) software. The viable (unstained) and nonviable (stained) oospores was expressed as a percentage of the total oospores examined, and the reported numbers are the average of three replications with their corresponding standard errors of the mean. The relationship between the trypan blue test and the plasmolysis method was determined by Pearson's correlation analysis in JMP (JMP version 12.0.1 on Windows 7).

Extraction and purification of DNA from spinach seed. DNA was extracted from spinach seed as described by Duressa et al. (2012). Briefly, 300 seeds taken from the individual seed lots were ground for approximately $45 \mathrm{~s}$ to a fine powder using an IKA A10 analytical grinding mill (IKA Laboratory). Between samples, the stainless steel grinding chamber of the mill was washed with deionized water, followed by rinsing with $70 \%$ ethanol. DNA extractions were conducted on four 200-mg fractions obtained from 300 ground seeds using a FastDNA kit following the manufacturer's protocol (MP Biomedicals), with the exception that the IKA A10 mill was used for sample homogenization. A $25-\mu l$ volume of extracted DNA was further purified using AMPure magnetic beads and a SPRI 96-Ring mMagnet Plate (Agencourt) to remove PCR inhibitors. The final elution was performed with $25 \mu l$ of nuclease-free water. The DNA concentration in the eluate was determined with a Qubit fluorimeter using the Qubit dsDNA HS Assay Kit (Life Technologies), with a detection range of $10 \mathrm{pg}$ to $100 \mathrm{ng} / \mu \mathrm{l}$. 
Conventional PCR and sequence analysis. For the PCR assay, a $1-\mu l$ volume of DNA template, extracted as above, was used to amplify a PCR product with $P$. effusa-specific primers (AS1 and PeR1) (Klosterman et al. 2014) in a Bio-Rad MJ Research PTC-200 thermal cycler. PCR reactions $(25 \mu \mathrm{l})$ included $200 \mathrm{nM}$ species-specific primers (AS1 and PeR1) and 1× GoTaq DNA Polymerase mix (Promega Corp.). Reactions were performed on a PTC-200 thermocycler under the following conditions: $94^{\circ} \mathrm{C}$ for $5 \mathrm{~min}$ and 35 cycles of $94^{\circ} \mathrm{C}$ for $30 \mathrm{~s}, 60^{\circ} \mathrm{C}$ for $30 \mathrm{~s}$, and $72^{\circ} \mathrm{C}$ for $30 \mathrm{~s}$. A final extension of $72{ }^{\circ} \mathrm{C}$ was used for $5 \mathrm{~min}$. The amplified product was loaded on $1.6 \%$ agarose gel. For sequence comparisons, the Peronosporaconserved primers UF1 (5'-TGAATGCGCATCGTGC-3') (Klosterman et al. 2014) and 655R ( $5^{\prime}$-ATGTGCGAGCCTAGACATCC-3') were used to amplify DNA template extracted from spinach seed, and sequence comparisons were conducted to determine matches with $P$. effusa (GenBank AF528560.1). DNA extracted from infected leaf tissue was used as positive control for PCR. The program BioEdit (Hall 1999) was used to align multiple sequences and generate ClustalW sequence comparisons (Thompson et al. 1994).

TaqMan assay (qPCR). A TaqMan assay was performed on a subset of 59 of the 82 seed lots, as described by Klosterman et al. (2014). The DNA extracted for this assay was purified using Agencourt AMPure beads and quantified with a Qubit fluorimeter (Life Technologies) and a Qubit dsDNA High Sensitivity (HS) Assay Kit (Life Technologies), using a volume of $2 \mu$ l per reaction. The $5^{\prime}$ end of the TaqMan probe (Pef1) for P. effusa was labeled with fluorescein and the $3^{\prime}$ end of the probe was labeled with minor groove-binding nonfluorescent quencher (Applied Biosystems). Species-specific primers (AS1 and PeR1) were used for this assay (Klosterman et al. 2014). The amplification master mix contained $900 \mathrm{nM}$ each of the species-specific primer pair, $0.4 \mu \mathrm{M}$ TaqMan probe, and 1× ABI Environmental Master Mix (Applied Biosystems) with PCR cycling conditions of $95^{\circ} \mathrm{C}$ for $10 \mathrm{~min}$ and 40 cycles of $95^{\circ} \mathrm{C}$ for $15 \mathrm{~s}$ and $60^{\circ} \mathrm{C}$ for $30 \mathrm{~s}$. The reactions were performed on a Light Cycler 480 II (Roche Diagnostics), with three technical replicates for each fraction. Samples with quantification cycle $(\mathrm{Cq})$ values $>38$ were considered negative for the detection of $P$. effusa. The copy number for each sample was determined as described by Klosterman et al. (2014), without subtraction of nonspecific amplification values from $P$. schachtii because only spinach seed was used.

\section{Results}

Analyses of seed lots by microscopy. Using the seed-wash approach, one or more oospores were detected in 13 of the 82 seed lots evaluated (Table 1). In 5 of the 13 lots, over 60 oospores per $75 \mu \mathrm{l}$ were detected (Table 1). Sporangiophores characteristic of $P$. effusa were detected in nine lots $(2,3,10,22,25,49,57,72$, and 80) (Table 1; Fig. 1A) and oospores were also detected in four of these seed lots $(22,25,57$, and 72$)$. Lastly, sporangia characteristic of Peronospora spp. were detected in three seed lots $(22,36$, and 77) and an oospore was detected in one of these samples (lot 22).

Morphologically, the oospores detected in the seed lots in these analyses were round and thick-walled, and had a smooth surface without protuberances (Fig. 1), similar to those described by Choi et al. (2007). The diameters of oospores varied from 17 to $37 \mu \mathrm{m}$, with an average size of 21 to $30 \mu \mathrm{m}$ (for lots 22, 24, 25, 29, 30, $37,56,57,72$, and 82; Table 1), similar to those described by Inaba et al. (1983) and Choi et al. (2007). Thus, oospores, sporangiophores, or sporangia that were characteristic of $P$. effusa (Fig. 1) were detected in $24 \%$ of the tested seed lots (Table 1). Of the 11 seed lots that were washed using 100 seeds per replicate, the results indicate that $110,10,256$, and 26 oospores per $50 \mu \mathrm{l}$ were detected in lots 22 , 25,29 , and 57, respectively (data not shown). In these particular seed lots, the total number of oospores recovered from the three replicates ranged from 28 to 1,940 (data not shown). In addition, low numbers

Table 1. Spinach seed lots identified as infested with Peronospora effusa in this study by morphological and molecular tests

\begin{tabular}{|c|c|c|c|c|c|c|}
\hline \multirow[b]{2}{*}{ Seed lot } & \multirow[b]{2}{*}{ Seeds $^{\mathbf{b}}$} & \multicolumn{3}{|c|}{ Detection of Peronospora $^{\text {a }}$} & \multicolumn{2}{|r|}{ Oospores } \\
\hline & & Microscopy & PCR $^{\mathrm{c}}$ & $\overline{q P C R}(\mathrm{Cq} \pm \mathrm{SE})^{\mathrm{d}}$ & $n^{\mathrm{e}}$ & Diameter $(\mu \mathrm{m} \pm \mathrm{SE})^{\mathrm{f}}$ \\
\hline 2 & 1,000 & $+(\mathrm{sp})$ & + & $\ldots$ & $\ldots$ & $\ldots$ \\
\hline 3 & 1,000 & $+(\mathrm{sp})$ & + & $\ldots$ & $\ldots$ & $\ldots$ \\
\hline 10 & 1,000 & $+(\mathrm{sp})$ & $\ldots$ & $\ldots$ & $\ldots$ & $\ldots$ \\
\hline 17 & 1,000 & $++(\mathrm{o})$ & $\ldots$ & $\ldots$ & $\mathrm{NR}^{\mathrm{g}}$ & $\ldots$ \\
\hline 22 & 1,000 & $++++(\mathrm{o}),+(\mathrm{sp}),+(\mathrm{s})$ & + & $\ldots$ & 138 & $30.4 \pm 0.76$ \\
\hline 24 & 1,000 & $++(\mathrm{o})$ & $\ldots$ & $35.69 \pm 0.88$ & 16 & $27.0 \pm 0.69$ \\
\hline 25 & 1,000 & $++++(\mathrm{o}),+(\mathrm{sp})$ & $\ldots$ & $35.78 \pm 0.25$ & 69 & $28.2 \pm 1.01$ \\
\hline 29 & 1,000 & $++++(\mathrm{o})$ & + & $\ldots$ & 180 & $28.0 \pm 0.55$ \\
\hline 30 & 1,000 & $++(0)$ & + & $\ldots$ & 31 & $27.6 \pm 0.92$ \\
\hline 36 & 1,000 & $+(s)$ & $\ldots$ & $35.57 \pm 0.25$ & $\ldots$ & $\ldots$ \\
\hline 37 & 1,000 & $+(\mathrm{o})$ & $\ldots$ & $35.94 \pm 1.43$ & 2 & $22.2 \pm 0.22$ \\
\hline 49 & 1,000 & $+(\mathrm{sp})$ & + & $34.02 \pm 0.33$ & $\ldots$ & $\ldots$ \\
\hline 56 & 1,000 & $+(\mathrm{o})$ & $\ldots$ & $35.28 \pm 0.12$ & 2 & $21.0 \pm 1.34$ \\
\hline 57 & 1,000 & $++++(\mathrm{o}),+(\mathrm{sp})$ & $\ldots$ & $32.71 \pm 1.2$ & 150 & $29.9 \pm 0.68$ \\
\hline 60 & 1,000 & $+(\mathrm{o})$ & + & $\ldots$ & 1 & 22.7 \\
\hline 69 & 500 & $+(\mathrm{o})$ & $\ldots$ & $33.62 \pm 0.46$ & 1 & 18.1 \\
\hline 72 & 500 & $++++(\mathrm{o}),+(\mathrm{sp})$ & $\ldots$ & $32.38 \pm 0.51$ & 68 & $30.2 \pm 0.61$ \\
\hline 77 & 500 & $+(s)$ & $\ldots$ & $37.25 \pm 0.20$ & $\ldots$ & $\ldots$ \\
\hline 80 & 1,000 & $+(\mathrm{sp})$ & $\ldots$ & $34.70 \pm 0.42$ & $\ldots$ & $\ldots$ \\
\hline 82 & 1,000 & $+(\mathrm{o})$ & $\ldots$ & $36.48 \pm 0.79$ & 2 & $30.2 \pm 0.44$ \\
\hline
\end{tabular}

a Symbols: $+(\mathrm{o})=$ detected one to two oospores, $+(\mathrm{s})=$ detected sporangia, $+(\mathrm{sp})=$ detected sporangiophores, $++(\mathrm{o})=$ detected several oospores, $++++(\mathrm{o})=$ detected numerous oospores and most were viable, and $+=$ positive to $P$. effusa using polymerase chain reaction (PCR).

b Number of seeds used to detect $P$. effusa from each seed lot using the wash off method (see Materials and Methods).

c PCR confirmation for seed lots 2 and 3 using primers UF1 forward and 655R. For seed lots 22, 29, 30, 49, and 60, the species-specific primers AS1 and PeR1 were used (see Materials and Methods).

${ }^{\mathrm{d}}$ Quantitative PCR; average quantification cycle $(\mathrm{Cq})$ values of TaqMan assay from four different fractions; SE = standard error calculated from four fractions of the same sample.

e Number of oospores detected from one $75-\mu 1$ volume of the suspended pellet.

f Average diameter of 14 oospores (for seed lots 22, 25, 29, 57, and 72); SE = standard error from 14 oospores, unless less than 14 (for seed lots 37,56 , and 82 ).

g Oospores in seed lot 17 were observed but the actual numbers of oospores/1,000 seeds were not recorded. 


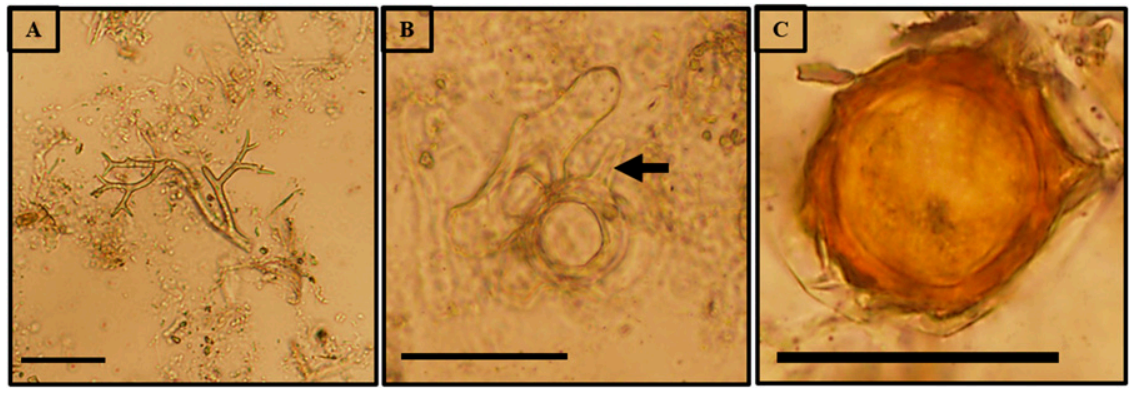

Fig. 1. Different stages of Peronospora effusa detected in spinach seed lots. A, Sporangiophores; B, immature oospore showing the oogonium with tapered base (arrow); and C, mature oospore. Scale bars $=50 \mu \mathrm{m}$.
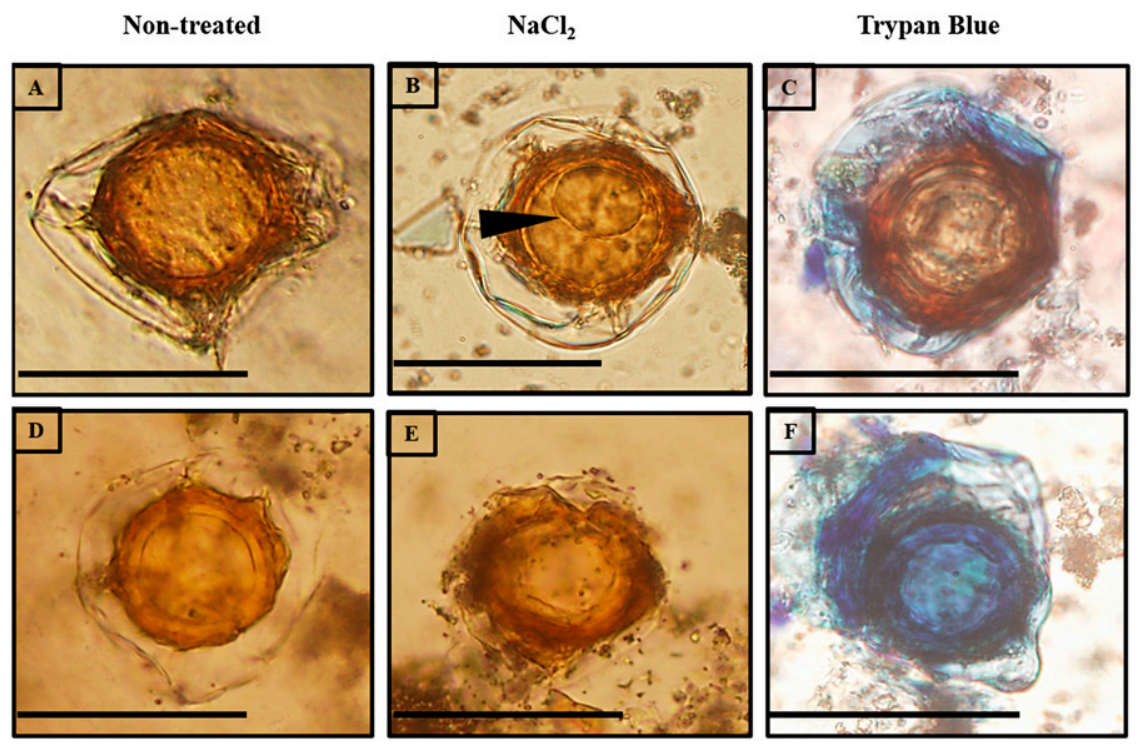

Fig. 2. Viability tests of Peronospora oospores by plasmolysis or trypan blue staining. A and D, Untreated oospores from seed lots 29 and 22 , respectively. B, Plasmolyzed oospore after 45-min exposure in $4 \mathrm{M} \mathrm{NaCl}$; the arrow shows the contraction of plasma membrane. E, Nonplasmolyzed oospore. C, Oospore excluding the trypan blue stain (viable). F, Oospore stained with trypan blue (nonviable). Scale bars $=50 \mu \mathrm{m}$.
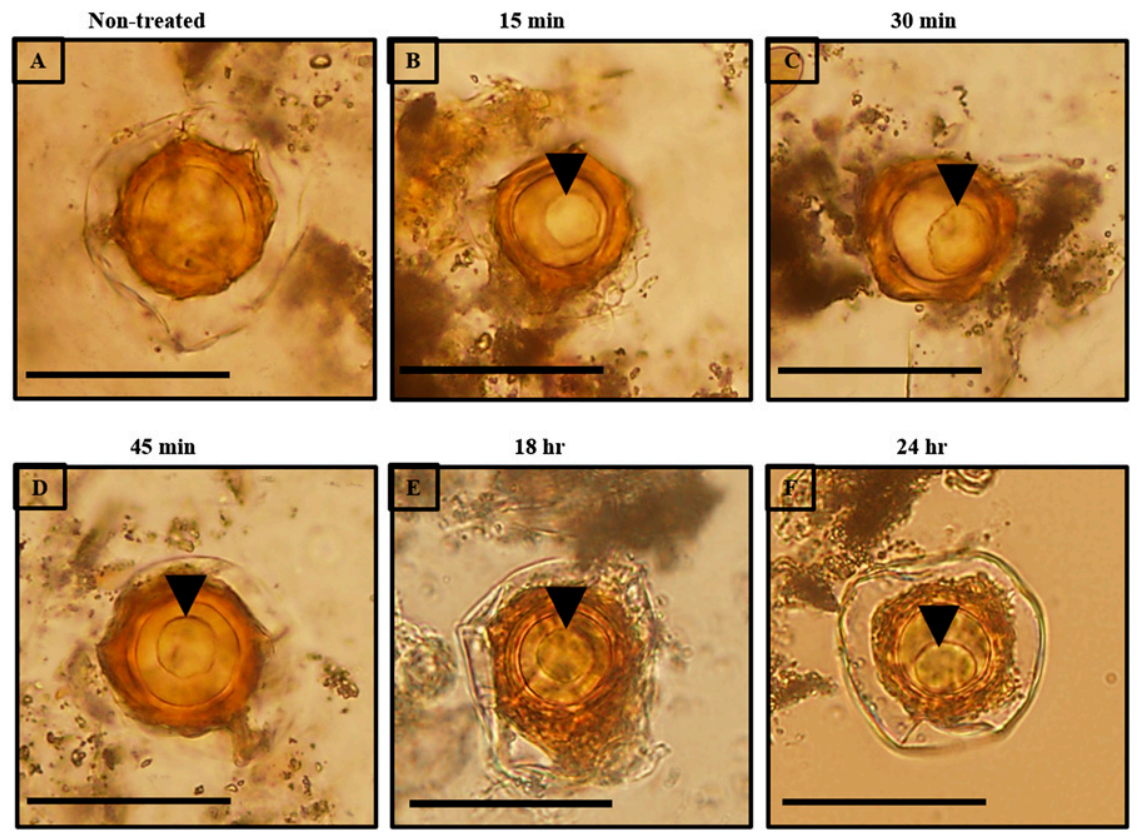

Fig. 3. Effect of $4 \mathrm{M}$ sodium chloride on oospores derived from spinach seed lots at different time points. A, Not treated; B, $15 \mathrm{~min} ; \mathrm{C}, 30 \mathrm{~min} ; \mathrm{D}, 45 \mathrm{~min}$; E, $18 \mathrm{~h}$; and F, $24 \mathrm{~h}$. Scale bars $=50 \mu \mathrm{m}$. 
of oospores $(<5)$ were detected in seed lots $37,56,60,69$, and 82 (data not shown). No oospores were detected in seed lots 2, 3, 10, 36, 49, 77, and 80 .

Plasmolysis tests. The cytoplasm of viable oospores contracted by exosmosis to form a ball-like structure when resuspended in the hypertonic solution ( $4 \mathrm{M} \mathrm{NaCl}$; Fig. 2B). Nonviable oospores were not plasmolyzed, because they had lost differential permeability of their plasma membrane, and the ball-like structure was not detected (Fig. 2E). Of the five intervals at which plasmolysis was evaluated (Fig. 3), shrinking of the cytoplasm, characteristic of plasmolysis, was observed as early as $15 \mathrm{~min}$ in the hypertonic solution (Fig. 3B). The number of oospores showing plasmolysis or the clarity of the reaction did not change between the 15-min (Fig. 3B) and 24-h (Fig. 3E) intervals. Similarly, the number of plasmolyzed oospores did not change between 15 and $45 \mathrm{~min}$, and even up to $24 \mathrm{~h}$ (data not shown). Of the five seed lots in which oospores were tested for plasmolysis $(22,25,29,57$, and 72$)$, two (22 and 29) contained more than $87 \%$ of viable oospores. Similarly, 77,65 , and $59 \%$ of viable spores were detected in lots 57,25 , and 72 , respectively (Fig. 4). In lots 22 and 29,87 and $89 \%$ of the oospores were plasmolyzed, respectively (Fig. 3B). In all, 66, 78, and $60 \%$ of the oospores plasmolyzed in lots 25,57 , and 72 , respectively (Fig. 4). Deplasmolysis was nearly instantaneous, occurring in less than $30 \mathrm{~s}$ in the presence of fresh water (Supplementary Video S1). More than 59\% of oospores were viable in each of the

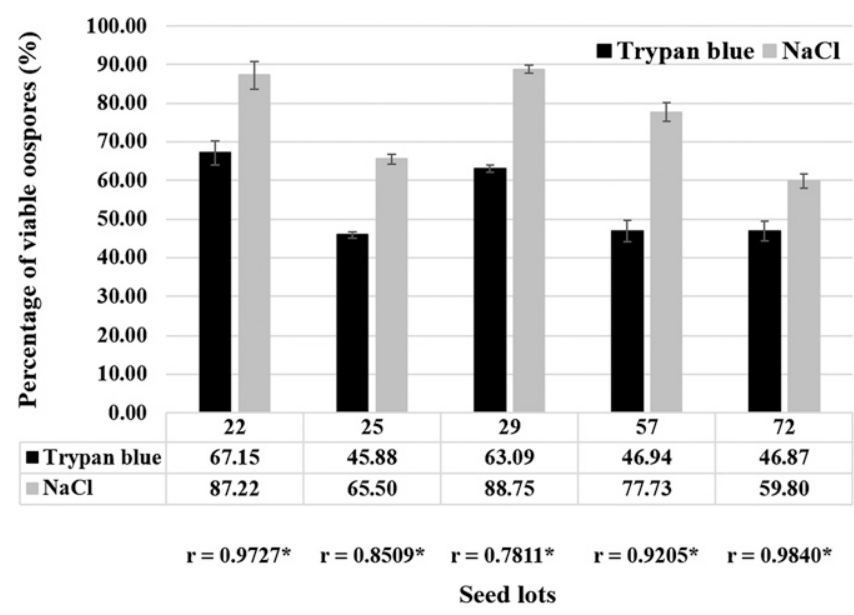

Fig. 4. Comparison of the plasmolysis and trypan blue staining techniques for analysis of oospore viability. The oospores of Peronospora effusa were derived from five different spinach seed lots. Bars represent the percentage of oospores determined as viable in the five different seed lots by plasmolysis (gray bars) or trypan blue stain (black bars). Bars indicate percentages determined as viable using each of the techniques and represent the average of three counts with standard error. An asterisk (*) represents viability data of oospores determined by both techniques (trypan blue and plasmolysis), which were positively correlated in the respective seed lots as determined by Pearson's correlation analysis (see Materials and Methods). seed lots (Fig. 4). Plasmolysis and deplasmolysis tests could not be performed on the oospore-positive seed lots in which there were inadequate numbers of oospores detected (lots 17, 24, 30, 37, 56, 60, 69, and 82; Table 1). An additional unreplicated test was conducted to determine viability of oospores by plasmolysis after high heat and steam (autoclave) treatment on oospores derived from seed lot 22, where abundant oospores were present. Nearly $10 \%$ of oospores detected following autoclave treatment remained viable (3 of 37) although, importantly, 74\% fewer oospores were detected from seed of the autoclave-treated group (data not shown).

Staining of oospores. In seed lots $22,25,29,57$, and 72, nearly $67,46,64,47$, and $47 \%$ of the oospores excluded the stain, respectively (Fig. 4), suggesting that these oospores were viable. The trypan blue staining test for oospore viability was not performed on those seed lots in which there were inadequate numbers of oospores for testing (lots 17, 24, 30, 37, 56, 60, 69, and 82; Table 1). The rate of detection of viable oospores was reduced by $20 \%$ when trypan blue staining was employed instead of the plasmolysis test, with the exception of seed lot 72 , where the reduction was $13 \%$. In this seed lot, most of the oospores were damaged relative to four other seed lots $(22,25,29$, and 57) and, thus, there were fewer false negatives. Additional tests were conducted to determine whether plasmolyzed oospores would stain upon treating with trypan blue. The shrunken plasma membrane of the oospore deplasmolyzed and excluded the stain (Supplementary Video S2).

PCR detection of $\boldsymbol{P}$. effusa and sequence analysis. Conventional PCR analysis was used to detect the presence of DNA from P. effusa in a subset of 17 seed lots (lots 1 through 9 and 22, 29, 30, $31,43,47,49$, and 60). These particular subsets were chosen for this analysis because they represented different levels of $P$. effusa detection, ranging from no detection of the pathogen to detection of oospores, sporangiophores, or sporangia by microscopy. Four different fractions of the ground seed from each lot were tested. All four fractions of five seed lots $(22,29,30,31$, and 43) were PCR positive, which can be observed by a bright band with a product size of $67 \mathrm{bp}$ (Fig. 5). At least one fraction of each of the seed lots tested was positive for $P$. effusa as in seed lots 47,49 , and 60 , in which two of the fractions yielded amplicons when subjected to PCR analyses (Fig. 5). The DNA extracted from $P$. effusa-infected leaf tissue was used as positive control, where the 67-bp amplicon was also detected (Fig. 5). This amplicon was absent in the water control. The DNA sequences of the amplified product from five seed lots $(2,3,4,8$, and 9) were $100 \%$ identical to publicly available $P$. effusa sequence (GenBank AF528560.1) (Supplementary Fig. S1).

qPCR (TaqMan) assay. Out of 59 seed lots tested, 56 were positive for $P$. effusa with the TaqMan assay $(\mathrm{Cq}<38)$. The assay using DNA template derived from three of the seed lots yielded $\mathrm{Cq}$ values $>38$ and were considered negative (Table 1; Supplementary Table $\mathrm{S} 2$ ). The $\mathrm{Cq}$ values of seed lots 25,57 , and 72 , in which more than 60 oospores were detected in each, were $35.78,32.71$, and 32.38 , respectively (Table 1). The ribosomal DNA (rDNA) copy numbers for lots 25,57 , and 72 were $239,3,435$, and 3,012, respectively. The $18 \mathrm{~S}$

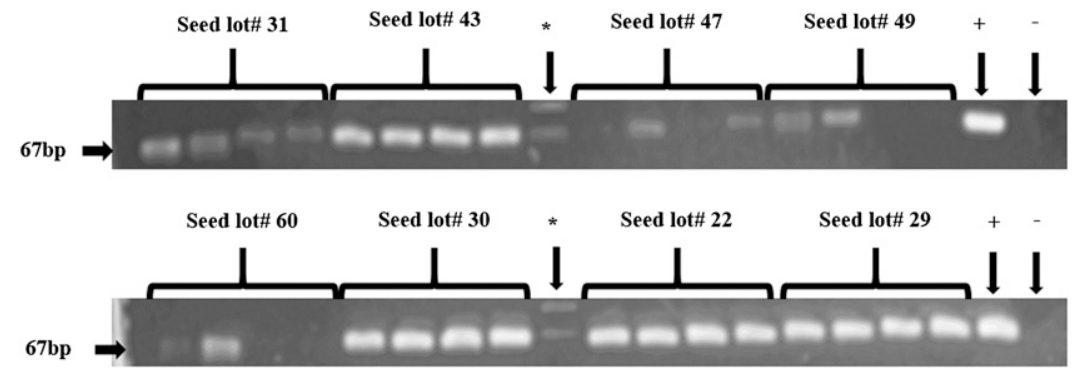

Fig. 5. Detection of the $18 \mathrm{~S}$ ribosomal DNA from Peronospora effusa in spinach seed lots by conventional polymerase chain reactions. The $P$. effusa-specific primer pair AS1 and Per1 (Klosterman et al. 2014) was used in all reactions. Four ground fractions for each seed lot were tested. Symbols: * $=$ molecular ladder, $+=$ positive control (DNA template extracted from $P$. effusa- infected spinach leaf tissue), and $-=$ negative control (sterile water, no DNA template control). 
rDNA copy number detected per seed lot sample ranged from 79 to 20,947 , with an average of 1,297 .

\section{Discussion}

The primary objectives of this current study examined whether contemporary commercial spinach seed lots harbored oospores and whether they were viable. Utilizing a seed-wash technique, $16 \%$ of the 82 seed lots were determined positive for oospores characteristic of $P$. effusa (Choi et al. 2007) and $24 \%$ were positive for either oospores, sporangiophores, or sporangia. In contrast, the $P$. effusa-specific qPCR (TaqMan) assay identified $95 \%$ of the seed lots as positive for $P$. effusa. Among the five seed lots evaluated for viability of the oospores, 46 and $60 \%$ of oospores were viable based on the trypan blue staining and plasmolysis tests, respectively.

The results of the sensitive qPCR assay, which had been applied previously to detect DNA from airborne sporangia of $P$. effusa (Klosterman et al. 2014), suggests that the $P$. effusa infestation levels are actually higher per seed lot than can be detected by microscopy. We were able to detect oospores in only 13 of 82 seed lots, because we took only a small subset of the seed (either 500 or 1,000 seeds) from each lot. Therefore, there is a high likelihood that oospores were present in the remaining seed lots but were not observed using the approach taken. Similar to the observations of Leach and Borthwick (1934) in spinach and Suryanarayana (1962) in pearl millet, sporangiophores were detected from seed washes of nine seed lots.

Determination of oospore viability from germination tests can be problematic and time consuming, with very low germination percentage (Erwin and McCormick 1971; Etxeberria et al. 2011; Inaba et al. 1983). The employment of the plasmolysis test along with trypan blue staining provided convenient and rapid alternative avenues to determine oospore viability in $P$. effusa. The effects of plasmolysis were quickly reversible with the addition of sterile, deionized water that restored the contracted plasma membrane to its original tensile form, thereby further demonstrating the viability of oospores. The results obtained in this study were consistent with those of Etxeberria et al. (2011), even though a different oomycete pathogen was examined in the work of Etxeberria et al. (2011).

The second test relied on the use of trypan blue staining. The absence of stain uptake by oospores was suggestive of viability that ranged from 13 to $31 \%$ in different seed lots. Viability tests using other types of stains, such as MTT, were not consistent (Etxeberria et al. 2011). Several studies (Ribeiro et al. 1975; Singh et al. 2004; Williams et al. 1980) have reported lower viability rates using staining techniques (ranging from 26 to $35 \%$ ) due to false positives. Trypan blue stain is routinely used as a cell stain to assess cell viability from the dye exclusion test (Bos et al. 2010; Strober 2001). In this study, we observed that plasmolyzed oospores were stain-phobic and the nonplasmolyzed oospores were stain-philic, suggestive of viability and nonviability, respectively. On occasion, however, some of the plasmolyzed oospores (viable) absorbed the stain, thereby showing false negatives (data not shown). Previous work of Tran et al. (2011) indicated that trypan blue enters macrophage cells that are viable and metabolically active. Similarly, Hu and El-Fakahany (1994) showed that trypan blue staining revealed high false negatives for cellular mortality or neural cells. Hence, the use of trypan blue staining as a marker of cell viability should be interpreted with caution. Perhaps this explains why oospore viability tested lower with trypan blue stain relative to the plasmolysis test. Despite the fact that the MTT, TTC, NBT, and trypan blue stains have been widely used to determine oospore viability, the subjectivity in reading the color and the existence of false positives or false negatives (for trypan blue) suggest that this technique is not entirely reliable for viability testing. Hence, plasmolysis is a better technique than trypan blue staining for determining viability of $P$. effus $a$ oospores.

The presence of viable oospores in commercial spinach seed lots as determined by this study indicates a potential mechanism by which $P$. effusa may be transmitted to new areas. Because of the widespread international spinach seed trade, the movement of new downy mildew races between regions and countries via infested seed is plausible. This finding adds important information on the epidemiology of spinach downy mildew. A similar observation was reported for the seedborne disease on cucurbits" downy mildew, caused by Pseudoperonospora cubensis, where the pathogen migrated from Southeast Asia to Europe and subsequently to the United States (Runge et al. 2011; Cohen et al. 2014). Downy mildews of pearl millet (caused by Sclerospora graminicola) and soybean (caused by Peronospora manshurica) are transmitted by seed infested with oospores (Lai et al. 2004; Safeeulla 1976) or mycelium (Suryanarayana 1962).

Once transmitted to a new region, $P$. effusa may be more likely to sexually recombine with different mating types, because homogenous strains of spinach downy mildew collected from one region may be less likely to form oospores when coinoculated on spinach than when combined with isolates obtained from different, more widely dispersed regions (Frinking et al. 1985). The resultant sexual recombination in these pathogen populations could lead to unique characteristics within the population, possibly even the production of new races with increased virulence and fungicide resistance. This may explain the remarkable change in the population structure of this pathogen over the past decade. In 2008, 2009, and 2010, race 11, race 12 , and race 13/14, respectively, were discovered (Feng et al. 2014). In 2014, race 15 was identified in California (Koike and Correll 2014). In 2011 and 2012, race 13 was predominant among the isolates collected in California. With this rapid change in population structure, no single cultivar is resistant to all races (Feng et al. 2014) and fungicide applications are increasingly important for the control of this disease in conventional spinach production (Abawi et al. 2014). Organically produced spinach is especially threatened due to the lack of efficacious fungicides that can be used for downy mildew control.

Even before the first reported seed transmission of $P$. effusa over three decades ago (Inaba et al. 1983) and appearance of new races of the pathogen, downy mildew was considered a major problem on spinach. However, the rate of seed transmission and impact of seed inoculum has remained elusive (Navazio and Colley 2007). Herein, we demonstrated that the present-day commercial spinach seed lots carry viable oospores. Seed are likely sources of primary inoculum for the disease in production fields, pathogen spread from the seed production areas to crop production areas, and potential sexual reproduction of the pathogen within production fields, assuming that the two mating types are introduced. Hence, seed treatments may be necessary to minimize transport of the long-lived oospores that may transmit new races and different mating types of the pathogen to new geographic areas and cause downy mildew outbreaks in previously resistant crops.

\section{Acknowledgments}

We thank R. Pena and L. Ochoa for their technical assistance and the California Leafy Green Research Program and the California Department of Food and Agriculture (grant SCB14043) for funding.

\section{Literature Cited}

Abawi, G., Gugino, B. K., Helms, M., McGrath, M., Mohler, C. L., Rangarajan, A., and Tingey, W. M. 2014. Production Guide for Organic Spinach. New York State IPM Publ. No. 139. Cornell University, Ithaca, NY.

Bos, J. I. B., Armstrong, M. R., Gilroy, E. M., Boevink, P. C., Hein, I., Taylor, R. M., Zhendong, T., Engelhardt, S., Vetukuri, R. R., Harrower, B., Dixelius, C., Bryan, G., Sadanandom, A., Whisson, S. C., Kamoun, S., and Birch, P. R. J. 2010. Phytophthora infestans effector AVR3a is essential for virulence and manipulates plant immunity by stabilizing host E3 ligase CMPG1. Proc. Natl. Acad. Sci. USA 107:9909-9914.

Byford, W. J. 1967. Host specialization of Peronospora farinosa on Beta, Spinacia and Chenopodium. Trans. Br. Mycol. Soc. 50:603-607.

Choi, Y.-J., Hong, S. B., and Shin, H. D. 2007. Re-consideration of Peronospora farinosa infecting Spinacia oleracea as distinct species, Peronospora effusa. Mycol. Res. 111:381-391

Choi, Y.-J., Klosterman, S. J., Kummer, V., Voglmayr, H., Shin, H.-D., and Thines, M. 2015. Multi-locus tree and species tree approaches toward resolving a complex clade of downy mildews (Straminipila, Oomycota), including pathogens of beet and spinach. Mol. Phylogenet. Evol. 86: 24-34.

Cohen, Y., Rubin, A. E., Galperin, M., Ploch, S., Runge, F., and Thines, M. 2014 Seed transmission of Pseudoperonospora cubensis. PLoS One 9:e109766.

Correll, J. C., Bluhm, B. H., Feng, C., Lamour, K., du Toit, L. J., and Koike, S. T. 2011. Spinach: Better management of downy mildew and white rust through genomics. Eur. J. Plant Pathol. 129:193-205. 
Duressa, D., Rauscher, G., Koike, S. T., Mou, B., Hayes, R. J., Maruthachalam, K., Subbarao, K. V., and Klosterman, S. J. 2012. A real-time PCR assay for detection and quantification of Verticillium dahliae in spinach seed. Phytopathology 102: 443-451.

Erwin, D. C., and McCormick, W. H. 1971. Germination of oospores produced by Phytophthora megasperma var. sojae. Mycologia 63:972-977.

Etxeberria, A., Mendarte, S., and Larregla, S. 2011. Determination of viability of Phytophthora capsici oospores with the tetrazolium bromide staining test versus a plasmolysis method. Rev. Iberoam. Micol. 28:43-49.

Feng, C., Correll, J. C., Kammeijer, K. E., and Koike, S. T. 2014. Identification of new races and deviating strains of the spinach downy mildew pathogen Peronospora farinosa f. sp. spinaciae. Plant Dis. 98:145-152.

Frinking, H. D., Harrewijn, J. L., and Greerds, C. F. 1985. Factors governing oospore production by Peronospora farinosa f. sp. spinaciae in cotyledons of spinach. Neth. J. Plant Pathol. 91:215-223.

Groves, C. T., and Ristaino, J. B. 2000. Commercial fungicide formulations induce in vitro oospore formation and phenotypic change in mating type in Phytophthora infestans. Phytopathology 90:1201-1208.

Hall, T. A. 1999. BioEdit: A user-friendly biological sequence alignment editor and analysis program for Windows 95/98/NT. Nucleic Acids Symp. Ser. 41: 95-98.

Hu, J., and El-Fakahany, E. E. 1994. An artifact associated with using trypan blue exclusion to measure effects of amyloid beta on neuron viability. Life Sci. 55: 1009-1016.

Inaba, T., Takahashi, K., and Morinaka, T. 1983. Seed transmission of spinach downy mildew. Plant Dis. 67:1139-1141.

Irish, B. M., Correll, J. C., Koike, S. T., and Morelock, T. E. 2007. Three new races of the spinach downy mildew pathogen identified by a modified set of spinach differentials. Plant Dis. 91:1392-1396.

Irish, B. M., Correll, J. C., Koike, S. T., Schafer, J., and Morelock, T. E. 2003. Identification and cultivar reaction to three new races of the spinach downy mildew pathogen from the United States and Europe. Plant Dis. 87:567-572.

Kjøller, R., and Rosendahl, S. 1998. Enzymatic activity of the mycelium compared with oospore development during infection of pea roots by Aphanomyces euteiches. Phytopathology 88:992-996.

Klosterman, S. J., Anchieta, A., McRoberts, N., Koike, S. T., Subbarao, K. V., Voglmayr, H., Choi, Y. J., Thines, M., and Martin, F. N. 2014. Coupling spore traps and quantitative PCR assays for detection of the downy mildew pathogens of spinach (Peronospora effusa) and beet (P. schachtii). Phytopathology 104:1349-1359.

Koike, S. T., Cahn, M., Cantwell, M., Fennimore, S., Lestrange, M., Natwick, E., Smith, R. F., and Takele, E. 2011. Spinach Production in California. Publication 7212. University of California Division of Agriculture and Natural Resources, Richmond, CA.

Koike, S. T., and Correll, J. C. 2014. Race 15: New spinach downy mildew race confirmed. Agriculture and Natural Resources, University of California. Online publication: http://ucanr.edu/blogs/blogcore/postdetail.cfm?postnum=15035

Lai, P. S., Lien, T. J., Chen, R. S., and Tsay, J. G. 2004. The occurrence of downy mildew of vegetable soybean and its detection by PCR. Plant Prot. Bull. 46: 155-162.

Leach, L. D., and Borthwick, H. A. 1934. Distribution of downy mildew mycelium in spinach fruits. Phytopathology 24:1021-1025.

LeStrange, M., and Koike, S. T. 2012. Spinach Downy Mildew. UC Statewide IPM Program. Publ. 3467. University of California Division of Agriculture and Natural Resources, Richmond, CA.

Lumsden, R. D. 1981. A nylon fabric technique for studying the ecology of Pythium aphanidermatum and other fungi in soil. Phytopathology 71: 282-285.

MacKay, R. 1957. The longevity of the oospores of onion downy mildew Peronospora Destructor (Berk.) Casp. Sci. Proc. R. Dublin Soc. 27:295-307.
McCarren, K. L., McComb, J. A., Shearer, B. L., and Hardy, G. E. S. J. 2009 Phosphite impact on the in vitro production and viability of selfed oospores by Phytophthora cinnamomi. For. Pathol. 39:124-132.

Montes-Borrego, M., Landa, B. B., Navas-Cortés, J. A., Muñoz-Ledesma, F. J., and Jiménez-Díaz, R. M. 2009. Role of oospores as primary inoculum for epidemics of downy mildew caused by Peronospora arborescens in opium poppy crops in Spain. Plant Pathol. 58:1092-1103.

Morelock, T. E. 1999. Spinach: Variety test and description. HortScience 34 987-988.

Navazio, J., and Colley, M. 2007. Principles and Practices of Organic Spinach Seed Production in the Pacific Northwest. Organic Seed Alliance, Port Townsend, WA.

Ribeiro, O. K., Erwin, D. C., and Zentmyer, G. A. 1975. An improved synthetic medium for oospore production and germination of several Phytophthora species. Mycologia 67:1012-1019.

Richards, M. C. 1939. Downy mildew of spinach and its control. Cornell Agric. Exp. Stn. Bull. 718:1-29.

Roongruangsree, U.-T., Kjerulf-Jensen, C., Olson, L. W., and Lange, L. 1988. Viability tests for thick walled fungal spores (ex: Oospores of Peronospora manshurica). J. Phytopathol. 123:244-252.

Runge, F., Choi, Y.-J., and Thines, M. 2011. Phylogenetic investigations in the genus Pseudoperonospora reveal overlooked species and cryptic diversity in the $P$. cubensis species cluster. Eur. J. Plant Pathol. 129:135-146.

Safeeulla, K. M. 1976. Serious epidemic of downy mildew on pearl millet in India. Indications of seed transmission. Seed Pathol. 9:3-4.

Sherf, A. F., and MacNab, A. A. 1986. Spinach. Pages 544-545 in: Vegetable Diseases and Their Control, 2nd ed. John Wiley \& Sons.

Singh, B. P., Gupta, J., Roy, S., and Rana, D. K. 2004. Production of Phytophthora infestans oospores in planta and inoculum potential of in vitro produced oospores under temperate highlands and subtropical plains of India. Ann. Appl. Biol. 144:363-370

Smith, P. G. 1950. Downy mildew immunity in spinach. Phytopathology 40: 65-68.

Smith, P. G., Webb, R. E., and Luhn, C. H. 1962. Immunity to race 2 of spinach downy mildew. Phytopathology 52:597-599.

Smith, P. G., Webb, R. E., Millett, A. M., and Luhn, C. H. 1961. Downy mildew on spinach. Calif. Agric. 15:5.

Strober, W. 2001. Trypan blue exclusion test of cell viability. Appendix 3B in: Current Protocols in Immunology. J. E. Coligan, B. E. Bierer, D. H Margulies, E. M. Shevach, and W. Strober, eds. John Wiley \& Sons, New York.

Suryanarayana, D. 1962. Occurrence of an unknown fungal mycelium inside the sound grains produced on partly formed green ears of bajra plants. Sci. Cult. 28:536

Sutherland, E. D., and Cohen, S. D. 1983. Evaluation of tetrazolium bromide as a vital stain for fungal oospores. Phytopathology 73:1532-1535.

Thompson, J. D., Higgins, D. G., and Gibson, T. J. 1994. CLUSTALW: Improving the sensitivity of progressive multiple sequence alignment through sequence weighting, position-specific gap penalties and weight matrix choice. Nucleic Acids Res. 22:4673-4680.

Tran, S.-L., Puhar, A., Ngo-Camus, M., and Ramarao, N. 2011. Trypan blue dye enters viable cells incubated with the pore-forming toxin HlyII of Bacillus cereus. PLoS One 6:e22876.

USDA. 2014. Vegetable 2013 Summary. United States Department of Agriculture National Agricultural Statistics Service, Washington, DC.

Van Der Gaag, D. J., and Frinking, H. D. 1997. Survival characteristics of oospore populations of Peronospora viciae f. sp. pisi in soil. Plant Pathol. 46:978-988

Williams, R. J., Pawar, M. N., and Huibers-Govaert, I. 1980. Factors affecting staining of Sclerospora graminicola oospores with triphenyl tetrazolium chloride. Phytopathology 70:1092-1096. 